\title{
The Impact of Culture on the Perception of Young Japanese and Germans in the Management of the Corona Crisis by their Government
}

\author{
Luca Kampe $^{1}$ - Véronique Goehlich ${ }^{1} \cdot$ Kirsten Wüst $^{1}$
}

Accepted: 19 November 2021 / Published online: 16 December 2021

(c) The Author(s), under exclusive licence to Springer Science+Business Media, LLC, part of Springer Nature 2021

\begin{abstract}
This article addresses the extent to which culture has an impact in crisis management at the government level, exemplified by the corona crisis in Germany and Japan. The cultural dimensions of the Global Leadership and Organizational Behavior Effectiveness study provide a central framework for the study, enabling a comparison of the cultures. The findings suggest that cultural principles can shape crisis management in practice. However, values and ideals are significantly modified by the crisis. Through our developed framework, the cultural and crisis barriers can be identified and thus solutions can be found to operate more efficiently a successful crisis management.
\end{abstract}

Keywords Culture $\cdot$ Crisis management · Corona crisis · Japan · Germany · Government

\section{Introduction}

The corona pandemic represents a transboundary crisis of global proportions. Societies from a variety of cultural backgrounds are faced with the major challenge of counteracting the pandemic and its negative consequences. Thereby, countries around the world are responding to the crisis in different ways. What is the reason why crises are handled differently and what role does culture play in this process? What influence do cultural practices and ideals have on the crisis management

Luca Kampe

lucakampe@gmail.com

Véronique Goehlich

veronique.goehlich@hs-pforzheim.de

Kirsten Wüst

kirsten.wuest@hs-pforzheim.de

1 Hochschule Pforzheim, Tiefenbronner Straße 65, 75175 Pforzheim, Germany 
approaches? This article investigates whether culture has an impact in crisis management at the government level, exemplified by the corona crisis in Germany and Japan. The goal of our study is to assess how the measures, policies and regulations issued by the Japanese and German governments were perceived and whether the respondents' observations can be reflected in the GLOBE dimensions. The study depicts therefore a snapshot from the perspective of the time when uncertainty was tremendous in both countries during the corona crisis, allowing us to assess what role culture plays during a crisis and examine to what extent people rely on their fundamental cultural patterns in crisis situations.

\section{Research Question}

The aim of the paper is to examine the impact of culture in the perception of crisis management in Japan and Germany. For this purpose, the paper assesses crisis management from the macro perspective at the government level during the corona crisis. In order to identify the cultural influence, the perceptions of one particular segment of the German and Japanese populations (18 to 26 years old undergraduate students) about the respective government's crisis management during the corona crisis are examined. The cultural dimensions of the GLOBE study provide a central framework for the paper by representing the culture-defining domains, enabling a comparison of the cultures. By comparing the research findings with the GLOBE dimensions' scores, it is possible to determine which cultural practices and ideals can dominate among young citizens during a crisis and therefore impact implementation of crisis management guidelines and measures, as well as which cultural traits are not represented. Thus, the central research question of the paper is:

To what extent is the perception of one particular segment of the German and Japanese population regarding the corona crisis management of their respective governments reflected in the results from the cultural dimensions of the GLOBE study?

\section{Corona Crisis Management in Germany and Japan}

\section{Germany}

The federal government's strategy for managing the pandemic is composed of various measures, which are based on three fundamental principles: containment, protection and impact mitigation (Robert Koch Institut, URL 1, 2021). A balanced approach is taken between restrictions in the economy and in social life on the one hand, and the containment of the virus spread and its resulting damage on the other hand. The measures taken by the federal government and the states are adjusted by loosening or tightening the measures depending on the situation of the infection incidence (Robert Koch Institut, URL 2, 2020). Based on the infection levels (see Fig. 1), the course of the corona crisis of 2020 in Germany and the associated measures to contain the spread of the infection can be divided into three phases.

Phase one encompasses the period from January 1st, 2020, with the emergence of the first corona case in Germany on January 27 th, followed by the peak of the 


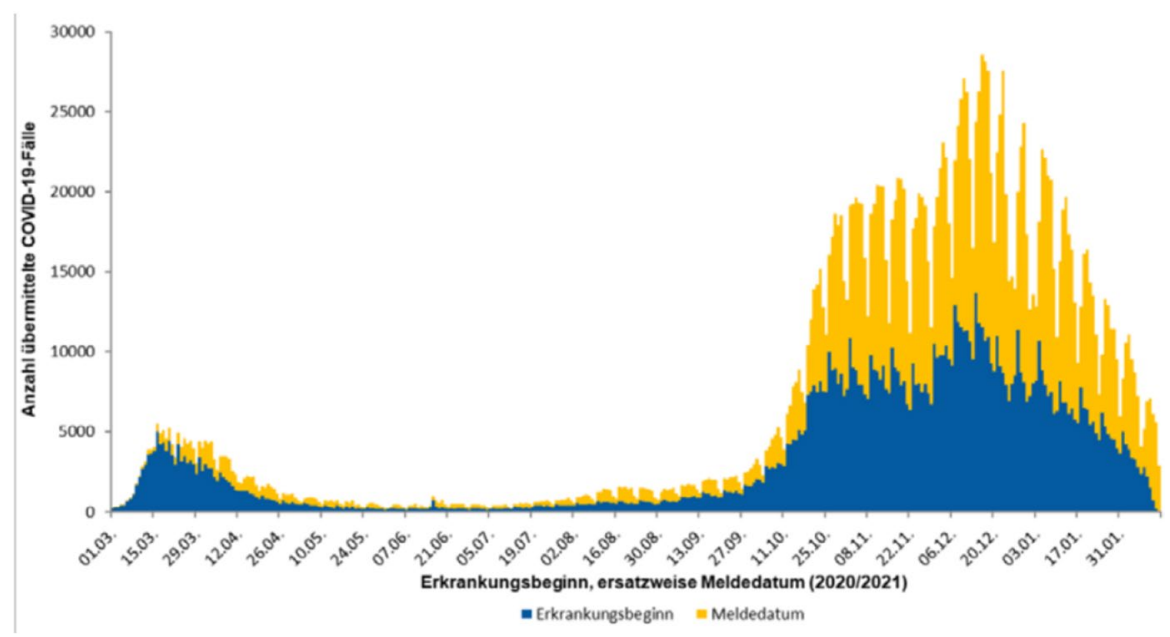

Fig. 1 Number of COVID-19 cases transmitted to the RKI over time for Germany from RKI (2021). Source: Robert Koch Institut, 2021, p. 4

first infection wave in March 2020 and the first lockdown on March 23rd, until the end of the first lockdown on May 4th. During the first lockdown, the federal and state governments agreed to restrict social contact by prohibiting meetings in public with more than two people outside of one's household, introduced distance regulations, closures of schools, restaurants, personal care-, leisure-, sports-, and cultural facilities as well as retail stores with the exception of grocery stores (Die Bundesregierung, URL, 2020; Robert Koch Institut, 2020, pp. 1-7).

Phase two begins on May 4th with the end of the first lockdown and the accompanying relaxation of the federal and state Corona measures, and ends on November 2nd with a partial lockdown, called " lockdown light," after the infection numbers have sharply risen again (Die Bundesregierung, 2020a, pp. 1-7).

Phase three begins on November 2 nd by tightening the measures and imposing further restrictions on public and private life. Schools, daycare centers, retail and wholesale establishments are exempt, remaining open while maintaining hygiene standards. On December 16th, a tighter lockdown went into effect provisionally until January 10th, closing schools, daycare centers, retail and wholesale establishments, with the exception of primary care stores and services. The 3rd phase ends on December the 31st with the peak in infection numbers viewing the year 2020 (Die Bundesregierung, 2020b, pp. 1-6; Die Bundesregierung, 2020c, pp. 1-6).

\section{Japan}

The corona crisis management of the Japanese government pursues the primary objective of limiting the infection spread as well as keeping the negative impact of the corona crisis on the economy and the society as low as possible. The government's approach is based on three fundamental principles. First, the identification and counteraction of infection clusters at an early stage. Second, assuring proactive 
screening, medical resources and support for intensive care. Thirdly, initiating a behavioral and mindset shift within the population towards a new lifestyle (Ministry of Health, Labour and Welfare of Japan, 2020a, pp. 1-2; Cabinet Public Relations Office, Cabinet Secretariat, URL 1, 2020). The government refers to its approach as the Japanese model, primarily seeking to change the behavior of the population through recommendations and suggestions rather than through imposing rules and laws in order to preserve the freedom of the population (Ministry of Health, Labour and Welfare of Japan, 2020b pp. 1-5). Depending on the level of infection and the level of burden on the health system a national state of emergency is declared in Japan in individual prefectures or nationwide without enforcing lockdown measures through bans to ensure the continuity of the freedom rights. By the declaration of a national state of emergency it is intended to appeal to the common sense of the population to refrain from risk situations by acting voluntarily in self-control following behavior recommendations. Measures include among others, encouraging people to remain at home, avoid public facilities and institution, cancel events, and refrain from expendable activities such as traveling, going out, dining in restaurants, as well as panic buying (Ministry of Health, Labour and Welfare of Japan, 2020c, pp. 1-9; Cabinet Public Relations Office, Cabinet Secretariat, URL 1, 2020; Cabinet Public Relations Office, Cabinet Secretariat, URL 2, 2020; Cabinet Public Relations Office, Cabinet Secretariat, URL 3, 2020). Based on the infection levels (see Fig. 2), the course of the corona crisis in Japan and the associated governmental countermeasures can be depicted in three phases for the entire year 2020 .

The first phase covers the period from January 1st through the first corona case on January 16th, with the peak of the first wave of infections in April, until the end of the first wave in early July. On April 7th, the state of emergency was declared, which initially applied to seven prefectures and was extended on April 16th throughout Japan until it was gradually reduced to individual prefectures and lifted completely on May 25th with the falling infection figures (Ministry of Health, Labour and Welfare of Japan, 2020c, pp. 1-9; Ministry of Health, Labour and Wel-fare of Japan, 2020d, pp. 1-7; Ministry of Health, Labour and Welfare of Japan, 2020e, pp. 1-12).

The second phase begins in July with sharply rising infection numbers and the start of the second wave peaking in August and ending in October. On the 5th of August, the National Institute of Infectious Diseases (NIID) evaluated the situation of the spread as alerting, similar to the situation in March and April. As a result, the population is being urgently asked to keep following the recommendations of the basic measures and refrain from potential risk situations (National Institute of Infectious Diseases, URL 1, 2020).

The third phase begins in early November with the start of the third wave and a sharp increase in new infections and ends on the 31 st of December with a peak in infections for the year 2020. Following the development, the government recommends that restaurants and shops should close earlier and further urgently insist the population to behave in self-discipline in order to comply with the corona measures. Starting the new year, on the 7th of January 2021, the national state of emergency was declared in metropolitan areas (National Institute of Infectious Diseases, URL 2, 2021). 
(1) No. of new cases of infection reported

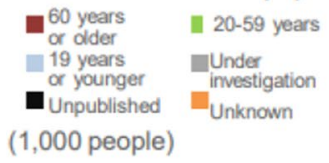

45

40

35

30

25

20

15

10

5

0

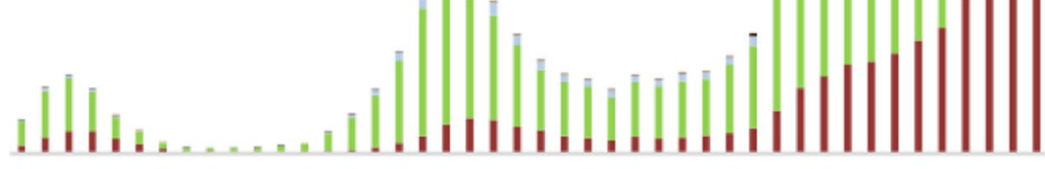

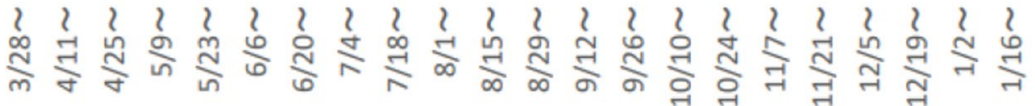

Fig. 2 Number of new Covid 19 cases of infection reported in Japan in 2020 until January 2021 from the NIID. Source: National Institute of Infectious Diseases, 2021, p. 2)

\section{Culture}

Various definitions of the term culture exist within literature without one definition prevailing. According to the GLOBE (Global Leadership and Organizational Behavior Effectiveness) study, one culture applies for a distinct group of people who have significant commonalities and differ notably from other groups of people through certain characteristics. Cultures can be distinguished by common attitudes, values, beliefs, and ideals, as well as through the nature of perceiving and understanding certain incidents. The characteristics are influenced by collective learning 
experiences throughout generations (House et al., 2004, pp. 15-16). To compare cultures and identify cultural differences at the national level, the differences in values must be made tangible. For this purpose, cultural dimensions are applied that represent themes affecting all countries similarly, yet the perspective on the themes varies depending on the culture. Based on a study for IBM (International Business Machines) in the 1970s, Hofstede developed six cultural dimensions (Hofstede et al., 2010, pp. 27-45). A further development of the culture dimensions originated from the GLOBE study program, from which the following nine dimensions emerged.

Beginning with performance orientation, this dimension measures the value of performance, and the level at which the striving for performance, improvement and innovation is and should be supported, motivated and recognized (House et al., 2004, pp. 239-246). The extent of foresighted planning and acting that is taking place and that should take place is examined by the dimension of future orientation (House et al., 2004, pp. 282-302). The next dimension is gender egalitarianism which measures the level to which gender roles are and should be equally distributed (House et al., 2004, pp. 347-360). Assertiveness assesses the degree of assertive, dominant and conflictual behavior that is and should be exercised towards other people (House et al., 2004, pp. 395-405). Collectivism is divided into two dimensions. For one, institutional collectivism gauges the extent of solidarity, common welfareoriented and group-oriented behavior and to what extent it should be supported, motivated and recognized, whereas in-group collectivism gauges the extent of the sense of belonging, cohesion, close attachment and pride in being part of the family and groups and how it should be pronounced (House et al., 2004, pp. 454-463). The dimension of power distance determines the degree of privileged positions, authorities and hierarchically structured distribution of power (from top to bottom) and at what degree they should be accepted and approved (House et al., 2004, pp. 513-536). Furthermore, the dimension of humane orientation captures how positive, generous and supportive interpersonal attitudes, interactions and behaviors are and should be motivated and recognized (House et al., 2004, pp. 569-570). The last dimension is uncertainty avoidance, which measures on what level the desire for continuity, structure and order is and should be pronounced - seeking to circumvent irregularities and unforeseen events through pre-existing guidelines, measures and standardized procedures (House et al., 2004, pp. 603-618).

\section{Crisis}

A crisis can take on different dimensions. It can affect individuals to groups, or impact entire systems, cultures, and nations, or even take on global proportions. Three factors are decisive for assessing a crisis. The first factor is the danger which is associated with the crisis and which must impair the essential characteristics and functions of the respective areas or actors, in matters such as security, health, property, systems, legislation or freedom, continuation of habitual activities. The second factor is immediacy, represented by the urgent need to find rapid countermeasures and solutions to cope with the current danger in an immediate period of time. The third factor is the unknown character of the crisis development, which includes 
the origin and the implications of the crisis both influencing the search for possible responses to overcome it (Boin et al., 2016, pp. 4-6, Kindle Edition).

\section{Crisis Management}

To successfully manage a crisis situation, government crisis leaders have to fulfill several essential functions (Boin et al., 2016, pp. 14-19, Kindle Edition; Holenweger et al., 2017, pp. 48-49):

- Staffing the crisis management team with individuals capable of working together while possessing the appropriate skills for the respective crisis phases (Preparing task).

- Comprehending the overall context of the crisis, encompassing the origin, impact, threat severity, and the affected segments of people or the areas of society (Sense making).

- Making and implementing multiple interrelated and critical decisions in short time intervals and under unknown circumstances, which furthermore have to be coordinated efficiently on different levels in order to avoid misunderstandings, disagreements or conflicts (Decision making).

- Communicating and explaining the crisis situation to ensure the population is informed about the origins, threat consequences and possible solutions. By expressing sensitivity, confidence and strength, confidence and optimism can be awakened within the population (Meaning making).

- Leading society back to normalcy once the crisis is over while taking responsibility for the handling of the crisis. The aim is to maintain the legitimacy of the government as a leader and the structures of society without creating a post-crisis situation in which the government is doubted and questioned or blame shifting occurs (Accountability).

- Reviewing the crisis events to identify and adapt weaknesses in the organizational, legal and political domains of the society for future crisis improvement (Learning task).

\section{Culture and Crisis Management}

Cultural impact in crisis management has been less featured in the literature, although the way crises are experienced, responded to and adapted to can differ depending on the culture (Björck, 2016, pp. 33-34). One study conducted by Bernhardsdóttir $(2015$, p. 8) investigated the impact of cultural differences in crisis management. Combining the cultural dimensions of the GLOBE study program with the grid-group cultural theory (GGCT), Bernhardsdóttir analyzed the impact of egalitarian, hierarchical, individualistic and fatalistic societies in crisis management.

The author Thompson (2018, pp. 5-7, Kindle Edition) summarized the gridgroup theory developed by Mary Douglas, referring to the book "Cultural Bias" from the year 1982. Societies can be culturally classified according to people's behavior within the society using the two dimensions grid and group, which describe the role of individuals and their relationships and actions in a society. 
The group dimension measures the degree a person is embedded in, controlled by, and determined by a self-contained and segregated group. The grid dimension measures the extent a person's actions and role are determined and bound by prescribed rules and policies. Based on the grid and group scales, societies can be divided into four categories (see Fig. 3).

The underlying foundation of Bernhardsdóttir's study is the independent variable of culture, which is derived by linking GLOBE's cultural dimensions with the GGCT. The GLOBE cultural dimensions can be reflected in the GGCT, hereby the dimensions power distance and collectivism split into institutional, and ingroup form the key pillars of the study. The cultural dimension of power distance is reflected in the grid scale, while the dimensions of institutional and in-group collectivism are reflected in the group scale (see Fig. 3).

The analysis and the results of the study underline that culture plays an important role in crisis management of a society. The four different types of culture (see Fig. 3), characterized by their own values and practices, have a specific impact on crisis decision-making processes and affect therefore the phases of crisis preparation and crisis responses (Bernhardsdóttir, 2015, pp. 159-164).

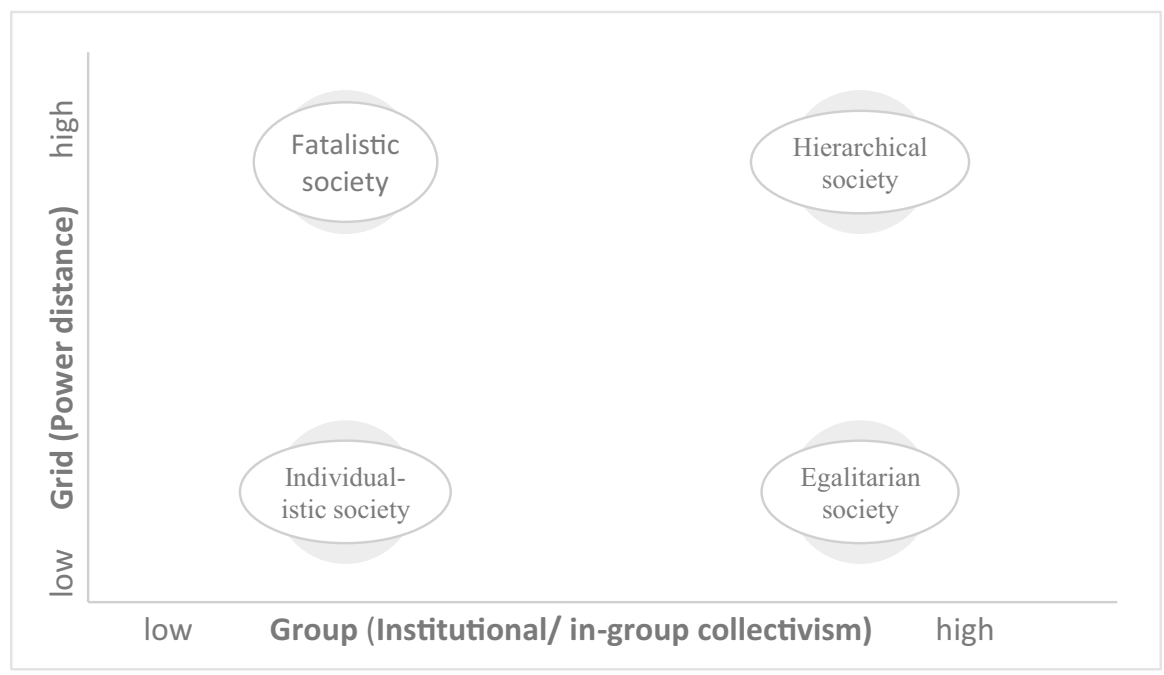

Fig. 3 Classification of cultural societies according to the GGCT and the GLOBE dimensions. Source: own illustration based on the GGCT presented by Thompson and the study of Bernhardsdóttir (Bernhardsdóttir, 2015; Thompson et al., 2018) 


\section{Cultural Analysis of the German and the Japanese Corona Crisis Management Approach}

\section{Methodology}

To investigate the research question, a quantitative survey was conducted among 18 to 26 years old undergraduate students in Germany and Japan (at least a completed school degree and at most a bachelor's degree). Only participants who met these criteria were selected for answering the survey questionnaire. The survey consists of questions to assess respondents' perception of the government's crisis management. The survey questions are aligned with the cultural dimensions of the GLOBE survey to reflect the different culture-shaping domains, while referring to the government's management of the corona crisis for the entire year 2020. More specifically, respondents are questioned on how they perceived the implementation of guidelines and measures to overcome the corona crisis ("How it was/ how it is") and how they think it should actually have been done ("How it should be"). This method is consistent with the GLOBE study approach of examining a culture by practices and values. The scales are adapted from the GLOBE study scales in order to be able to compare our results with the GLOBE dimensions.

The German and Japanese surveys were created through the platform Surveymonkey and shared via a weblink. The survey was translated from German, into English and then into Japanese with the help of four Japanese people, including students and former students from the Hiroshima University of Economics and a freelance translator. A pretest with several people was conducted for each of the two versions of the survey. The German survey was launched on the $17^{\text {th }}$ of December 2020 and the Japanese version on the $6^{\text {th }}$ of January 2021. Both were closed on January $29^{\text {th }}$, 2021. A second run of the survey was carried out for Germany on June $21^{\text {st }}, 2021$, until July $29^{\text {th }}, 2021$, to capture a relatively similar total number of respondents in Germany compared to Japan. A summary of the course of the corona crisis until the launch of the first survey was added, so that in the second run the respondents could put themselves into the exact same position of the respondents during the first run. A total of 108 people in Japan and 96 people from Germany representing the target group completed the survey. The analysis was carried out by using SPSS. Further information on the respondents' demographics is provided by the following two Tables 1 and 2 .

Table 1 Gender distribution of the respondents in Germany and Japan

\begin{tabular}{lll}
\hline Gender & Germany & Japan \\
\hline Male & $56(58.3 \%)$ & $61(56.5 \%)$ \\
Female & $37(38.5 \%)$ & $46(42.6 \%)$ \\
Diverse & $3(3.1 \%)$ & $1(0.9 \%)$ \\
\hline
\end{tabular}

Own illustration based on the survey data 
Table 2 Are of residence distribution of the respondents in Germany and Japan

\begin{tabular}{lll}
\hline Area of residence & Germany & Japan \\
\hline Rural community $(X<5000)$ & $14(14.6 \%)$ & $2(1.9 \%)$ \\
Small town $(5000 \leq X<20,000)$ & $16(16.7 \%)$ & $10(9.3 \%)$ \\
Medium sized town $(20,000 \leq X<100,000)$ & $31(32.3 \%)$ & $42(38.9 \%)$ \\
Large city $(100,000 \leq X<1,000,000)$ & $30(31.3 \%)$ & $28(25.9 \%)$ \\
Metropolis $(X \geq 1,000,000)$ & $5(5.2 \%)$ & $26(24.1 \%)$ \\
\hline
\end{tabular}

Own illustration based on the survey data

\section{Comparison of the Research Results with the Cultural Dimensions of GLOBE}

The objective of the analysis is to find out to which extent the target group's perceptions in Germany and Japan regarding the respective government's corona crisis management is reflected in the results of the GLOBE dimensions. A quantitative survey to assess the cultural dimensions was conducted to enable the comparison with the GLOBE scores in the respective dimensions per country using the two-sided one-sample T-test. Accordingly, the following hypotheses for each dimension and country were tested to ascertain whether the mean value of the survey dimensions are equal to or close to the mean value of the GLOBE dimensions.

HO: The mean value of the respective survey dimension score is equal to the GLOBE dimension score

H1: The mean value of the respective survey dimension score is not equal to the GLOBE dimension score

In the GLOBE study, West and East Germany were analysed separately. For comparison with the survey scores, a weighted average was calculated for Germany based on the 2004 population figures for West and East Germany (Schulz, 2004, p. 473).

The results were calculated with a confidence interval of $95 \%$ and are presented for Japan in Table 3 for the practices and Table 4 for the values, while the results for Germany are displayed in Table 5 for the practices and Table 6 for the values.

\section{Future Orientation}

For Japan, there is a significant difference in the dimension future orientation between the survey scores and the GLOBE dimension scores in practice under condition $\mathrm{t}(107)=-5.281, \mathrm{p}=<0.001$ and in values under condition $\mathrm{t}(107)=2.671$, $\mathrm{p}=0.009$. Similarly, for Germany, there is a significant difference in practice under condition $\mathrm{t}(95)=-9.894, \mathrm{p}=<0.001$ and in values under condition $\mathrm{t}(95)=5.579$, $\mathrm{p}=<0.001$. Consequently, culture-driven future orientation does not match in Japan and Germany with crises-driven future orientation in practice or values. 
Table 3 Significant difference results between the survey scores and the GLOBE dimensions for practices in Japan

\begin{tabular}{lllllll}
\hline $\begin{array}{l}\text { Dimension (Prac- } \\
\text { tice) }\end{array}$ & Survey score & GLOBE score & $\mathrm{T}$ & $\mathrm{df}$ & Sig (2-tailed) & Results \\
\hline $\begin{array}{l}\text { Future orientation } \\
\text { Humane orientation }\end{array}$ & 3.35 & 4.29 & -5.281 & 107 & $<.001$ & $\begin{array}{c}\text { Significant difference } \\
\text { No significant dif- } \\
\text { ference }\end{array}$ \\
$\begin{array}{l}\text { Assertiveness } \\
\begin{array}{l}\text { Institutional col- } \\
\text { lectivism }\end{array}\end{array}$ & 3.82 & 3.59 & -0.381 & 107 & .704 & $\begin{array}{c}\text { Significant difference } \\
\text { Significant difference }\end{array}$ \\
$\begin{array}{l}\text { In-group collectiv- } \\
\text { ism }\end{array}$ & 4.42 & 5.19 & -6.212 & 107 & $<.001$ & $\begin{array}{c}\text { No significant dif- } \\
\text { ference }\end{array}$ \\
$\begin{array}{l}\text { Power distance } \\
\begin{array}{l}\text { Uncertainty avoid- } \\
\text { ance }\end{array}\end{array}$ & 4.37 & 4.63 & -7.044 & 107 & $<.001$ & $\begin{array}{c}\text { Significant difference } \\
\text { No significant dif- } \\
\text { ferfonce } \\
\text { tation }\end{array}$ \\
\hline
\end{tabular}

own illustration based on the GLOBE study (House et al., 2004)

Table 4 Significant difference results between the survey scores and the GLOBE dimensions for values in Japan

\begin{tabular}{|c|c|c|c|c|c|c|}
\hline Dimension (Value) & Survey score & GLOBE score & $\mathrm{T}$ & df & Sig (2-tailed) & Results \\
\hline Future orientation & 5.64 & 5.25 & 2.671 & 107 & .009 & Significant difference \\
\hline Humane orientation & 4.30 & 5.41 & -6.305 & 107 & $<.001$ & Significant difference \\
\hline Assertiveness & 5.20 & 5.56 & -2.485 & 107 & .014 & Significant difference \\
\hline $\begin{array}{l}\text { Institutional col- } \\
\text { lectivism }\end{array}$ & 5.81 & 3.99 & 13.217 & 107 & $<.001$ & Significant difference \\
\hline $\begin{array}{l}\text { In-group collectiv- } \\
\text { ism }\end{array}$ & 6.04 & 5.26 & 6.031 & 107 & $<.001$ & Significant difference \\
\hline Power distance & 3.68 & 2.86 & 5.381 & 107 & $<.001$ & Significant difference \\
\hline $\begin{array}{l}\text { Uncertainty avoid- } \\
\text { ance }\end{array}$ & 5.01 & 4.33 & 6.666 & 107 & $<.001$ & Significant difference \\
\hline $\begin{array}{l}\text { Performance orien- } \\
\text { tation }\end{array}$ & 5.84 & 5.17 & 6.092 & 107 & $<.001$ & Significant difference \\
\hline
\end{tabular}

own illustration based on the GLOBE study (House et al., 2004)

It is noticeable that in both countries the survey scores in practice are lower than the GLOBE dimension scores, and that for both countries in the desired value the survey scores are higher than the GLOBE dimension scores. The survey scores show that the young populations in both Germany and Japan tend to perceive rather a short-term approach in the government's efforts to tackle the corona crisis with the score of 3.35 in Japan and 2.77 in Germany, whereas a more long-term approach is desired by the target groups indicated by the score of 5.64 in Japan and 5.69 in Germany. 
Table 5 Significant difference results between the survey scores and the GLOBE dimensions for practices in Germany

\begin{tabular}{lllllll}
\hline $\begin{array}{l}\text { Dimension (Prac- } \\
\text { tice) }\end{array}$ & Survey score & GLOBE score & $\mathrm{T}$ & $\mathrm{df}$ & Sig (2-tailed) & Results \\
\hline $\begin{array}{l}\text { Future orientation } \\
\text { Humane orientation }\end{array}$ & 3.23 & 4.21 & -9.894 & 95 & $<.001$ & $\begin{array}{l}\text { Significant difference } \\
\text { No significant dif- } \\
\text { ference }\end{array}$ \\
$\begin{array}{l}\text { Assertiveness } \\
\begin{array}{l}\text { Institutional col- } \\
\text { lectivism }\end{array}\end{array}$ & 4.08 & 4.58 & 0.057 & 95 & .955 & Significant difference \\
$\begin{array}{l}\text { In-group collectiv- } \\
\text { ism }\end{array}$ & 4.97 & 3.75 & -3.310 & 95 & .001 & Significant difference \\
$\begin{array}{l}\text { Power distance } \\
\begin{array}{l}\text { Uncertainty avoid- } \\
\text { ance }\end{array}\end{array}$ & 4.69 & 4.11 & 5.268 & 95 & $<.001$ & Significant difference \\
$\begin{array}{l}\text { Performance orien- } \\
\text { tation }\end{array}$ & 4.43 & 5.21 & 6.676 & 95 & $<.001$ & Significant difference \\
\hline
\end{tabular}

own illustration based on the GLOBE study (House et al., 2004)

Table 6 Significant difference results between the survey scores and the GLOBE dimensions for values in Germany

\begin{tabular}{lllllll}
\hline Dimension (Value) & Survey score & GLOBE score & $\mathrm{T}$ & $\mathrm{df}$ & $\mathrm{Sig}$ (2-tailed) & Results \\
\hline Future orientation & 5.69 & 4.92 & 5.579 & 95 & $<.001$ & Significant difference \\
Humane orientation & 4.89 & 5.46 & -4.817 & 95 & $<.001$ & Significant difference \\
Assertiveness & 5.32 & 3.12 & 17.593 & 95 & $<.001$ & Significant difference \\
$\quad \begin{array}{l}\text { Institutional collectiv- } \\
\quad 5.79\end{array}$ & 4.80 & 6.802 & 95 & $<.001$ & Significant difference \\
$\quad$ ism & & & & & & \\
$\quad \begin{array}{l}\text { In-group collectivism } \\
\text { Power distance }\end{array}$ & 6.16 & 5.19 & 8.772 & 95 & $<.001$ & Significant difference \\
$\quad \begin{array}{l}\text { Uncertainty avoid- } \\
\text { ance }\end{array}$ & 5.68 & 3.43 & 24.663 & 95 & $<.001$ & Significant difference \\
$\begin{array}{l}\text { Performance orienta- } \\
\quad \text { tion }\end{array}$ & 6.41 & 6.03 & 4.434 & 95 & $<.001$ & Significant difference \\
\hline
\end{tabular}

own illustration based on the GLOBE study (House et al., 2004)

\section{Humane Orientation}

There is no significant difference between the survey score and the GLOBE score in practice for Japan by $t(107)=-0.381, p=0.704$. The same applies for the target group in Germany, $\mathrm{t}(95)=0.057, \mathrm{p}=0.9555$. However, the survey scores and the GLOBE scores differ significantly from each other in the values for Japan indicated by $\mathrm{t}(107)=-6.305, \mathrm{p}=<0.001$ and for Germany by $\mathrm{t}(95)=-4.817$, $\mathrm{p}=<0.001$. Accordingly, for both Germany and Japan, the culturally derived 
human orientation matches the one taking place during the corona crisis in practice, whereas for the desired values it does not match.

Japan's relatively neutral survey score (4.23) in practice indicates that the target group is similarly concerned about their own well-being and the well-being of others during the corona crisis, with a bias toward the well-being of others. Germany's target group on other hand is rather concerned about their own well-being, with a survey score of 3.23. In contrast, the GLOBE value scores of 5.41 in Japan and 5.46 in Germany are both in the high range, indicating that culturally, the population desires a high level of thoughtfulness toward others. Meanwhile, during the corona crisis, the value is significantly lower at 4.3 in Japan and 4.89 in Germany.

\section{Assertiveness}

The Japanese target group shows a significant difference in the assertiveness dimension in practice by $\mathrm{t}(107)=-6.212, p<0.001$ and in the values by $\mathrm{t}(107)=-2.485$, $p=0.014$ between the survey scores and the GLOBE dimensions. The same is true for Germany in practice by $\mathrm{t}(95)=-3.310, p=0.001$ and in the values under condition $\mathrm{t}(95)=17.593, p=<0.001$. Therefore, in neither country a match between the culture-related assertiveness and the assertiveness during the corona crisis in practice and values is prevailing.

The survey dimensions score in practice (2.82) indicates a relatively loose implementation of the guidelines and measures in Japan, while the implementation in Germany is rather balanced from the target group's perspective, reaching a relatively neutral score of 4.08. For both countries, however, the target groups desire a more dominant and stricter implementation of the Corona guidelines and measures. The desired score amounts to 5.2 in Japan and to 5.32 in Germany.

\section{Institutional Collectivism}

The results of the target group in Japan show a significant difference between the survey scores and the GLOBE scores in practice by $\mathrm{t}(107)=-7.044, p=<0.001$, and in the values by $\mathrm{t}(107)=13.217, p=<0.001$. The same is shown by the results of the German target group under the condition $\mathrm{t}(95)=5.268, p=<0.001$ in the practice and in the values with $\mathrm{t}(95)=6.802, p=<0.001$. Consequently, culture is not reflected in practice from the respondents' point of view, and neither in the values of the two target groups regarding institutional collectivism during the corona crisis.

From the perspective of the Japanese target group, the government pursues a rather balanced approach during the corona crisis between the protection of the general public and the wellbeing of the few, as represented by the survey score of 3.99. For the German target group, the government tends to protect the wellbeing of the general public, compared to Japan with the score of 4.71. It is noticeable that for both countries the value score is in the high range, 5.81 in Japan and 5.79 in Germany, and thus both exceed the GLOBE score. Hence, the two target groups demand a crisis management government that focuses on the general well-being. 


\section{In-group Collectivism}

The practice survey score corresponds to the GLOBE score for Japan under the condition $\mathrm{t}(106)=-1.375, p=0.172$. The in-group collectivism during the corona crisis thus matches the culture-related one. In contrast, the value comparison shows no match, $\mathrm{t}(107)=6.031, p=<0.001$. Germany, on the other hand, shows no cultural and crisis-related match in either practices $\mathrm{t}(95)=6.676, p=<0.001$ or values $\mathrm{t}(95)=8.772, p=<0.001$.

The practice in-group survey score is 4.42 in Japan and 4.97 in Germany. Thus, the implemented in-group collectivism is relatively neutral in both countries, with a tendency to increased precaution towards corona risk groups. In contrast, the desired value in both countries is higher in comparison with 6.04 in Japan and 6.16 in Germany. The two survey value scores exceed the GLOBE value scores indicating a particularly desired solidarity and cohesion towards risks groups by the respondents during the corona crisis.

\section{Power Distance}

Power distance shows no relationship in practice in Japan under the condition $\mathrm{t}(107)=-10.154, p=<0.001$ and in the values under the condition $\mathrm{t}(107)=5.381$, $p=<0.001$. No relationship is likewise found for Germany in the practice, $\mathrm{t}(95)=-18.056, p=<0.001$, and in the values, $\mathrm{t}(95)=8.725, p=<0.001$.

The GLOBE practice scores for Japan (5.11) and Germany (5.30) appear to be both high, indicating that decision-making power in both societies tends to be distributed hierarchically and that decisions are generally accepted and followed by the population. The practice scores fall lower during the corona crisis in Japan (3.37) and in Germany (2.88) reflecting instead that measures are more likely to be challenged in the face of disagreement rather than followed. The desired GLOBE value score of Japan (2.86) and of Germany (2.57) shows that, culturally, an even distribution of power is desired by the population, as is the questioning of decisions in the case of disagreements. With 3.68 in Japan and 4.09 in Germany, the desired survey value scores exceed the respective GLOBE scores.

\section{Uncertainty Avoidance}

The cultural driven uncertainty avoidance matches the uncertainty avoidance in Japan during the corona crisis for the practice value, $\mathrm{t}(107)=-0.251, p=0.082$. In contrast, there is a significant difference between the survey score and the GLOBE score in the values, $\mathrm{t}(107)=6.666, p=<0.001$. For Germany, there is no match in practice by $\mathrm{t}(95)=-4.573, p=<0.001$ and in values by $\mathrm{t}(95)=24.663, p=<0.001$.

For Japan, the practice scores of GLOBE (4.07) and of the survey during the corona crisis (4.04) are both in the relative neutral range, reflecting a balanced culture-driven and crisis-driven approach between uncertainty avoidance and risktaking in practice. For Germany, the survey score (4.69) is below the high GLOBE score of 5.21. Both target groups, with a high value of 5,01 in Japan and 5,68 in Germany, prefer to be more comprehensively informed and desire more restrictive 
guidelines and measures aimed at avoiding risks during the corona crisis. It should be noted that both survey scores in the values within this dimension exceed the GLOBE scores.

\section{Performance Orientation}

The last dimension, performance orientation, shows no significant difference between the survey scores and GLOBE scores in practice for Japan, $t(107)=0.982$, $p=0.329$. Thus, the culture-related and crisis-related performance orientation matches in practice. However, a significant difference for Japan is found in the value, $\mathrm{t}(107)=6.092, p=<0.001$. For Germany, there is a significant difference between the survey scores and GLOBE scores both in practice by $\mathrm{t}(95)=2.360, p=0.02$ and in the values under the condition $\mathrm{t}(95)=4.434, p=<0.001$.

The practice survey scores for Japan $(4,34)$ and for Germany $(4,43)$ are relatively neutral, indicating that a balanced approach to adapting the corona guidelines and measures according to the development in the corona crisis is being taken and that, according to the respondents, the general public is reasonably compliant with the corona guidelines and measures. However, the high desired values in Japan $(5,84)$ and Germany $(6,41)$ show that the respondents demand a more performance-oriented containment of the corona crisis carried out by the governments as well as by the population through more continuous adaptation of the corona policies and measures and increased compliance among the populations.

\section{Outcomes}

By comparing the GLOBE scores and the survey scores in the culture-defining dimensions, the dimensions in which cultural practices and values match crisisrelated practices and values during the corona crisis are assessed from the perspective of the young population, indicating a cultural influence on crisis management in Germany and Japan. No significant difference means that the null hypothesis does not need to be rejected and indicates that culture could have influenced crisis behavior and crisis management in the respective dimension. A significant difference implies that culture is not influencing crisis behavior and crisis management in the respective dimension, indicating that crisis-related elements are overweighting the cultural elements.

The significant difference results suggest that the values and ideals of the population have changed as a result of the corona crisis, causing specific crisis elements to override expected and fundamental cultural behavior and mindsets. The deviation from the cultural patterns is expressed in the dimension future orientation in that the two young target groups demand a longer-term orientation of guidelines and measures. In Institutional Collectivism, it is shown by the target groups demand that the protection of the general public should be of top priority. In the dimension in-group collectivism, the change shows that in both countries the increased desire that coronary risk groups in particular should be treated more cautiously. For power distance it is indicated by a change in the desire towards a more centralized crisis management and a stricter following without doubt of the 
guidelines and measures by the population. The performance orientation dimension indicates a shift towards a stronger demand for continuous adaptation of the corona guidelines and measures and for increased compliance by the population in order to achieve the best possible containment outcomes. In the uncertainty avoidance dimension, the change is reflected in a desire for more restrictive guidelines and measures and extensive information communication. Conversely, the humane orientation is lower, resulting in a decrease in thoughtfulness toward others within both countries. In the dimension assertiveness, the change is reflected in that the target group in Germany demands a stricter enforcement of the guidelines and measures by the government during the corona crisis, while for Japan the demand is lower than culturally expected.

In the literature as an example, a paper investigated the shift of values in the light of the corona crisis with the focus on interactions in social media. The authors' findings suggest that the emotional interactions in social media can have a contagious character and thus, with the negative associations of the corona crisis, change the values of the population towards an increased desire for more security and more traditional approaches up to impacts and changes in political, social and economic values and desires (Steinert, 2020, pp. 1-10).

The results in the practice scores, on the other hand, show in which cultural dimensions the culture could have subconsciously shaped and thus dominated the crisis management of the government and the crisis behavior of the population. Culture and crisis management match in the following four dimensions in Japan: humane orientation, in-group collectivism, uncertainty avoidance and performance orientation.

In contrast, the survey scores for the dimensions future orientation, assertiveness, institutional collectivism and power distance, are significantly lower compared to the GLOBE scores and therefore do not match. This shows that in practice the crisis management of the government and the crisis behavior of the population in Japan is detached from the cultural principles within these dimensions. Contrary to cultural expectations, a more short-term approach to corona crisis management is adopted in practice along a looser implementation of the guidelines and measure through a more decentralized crisis management. Moreover, a more balanced approach to safeguarding the common good and the few is chosen.

In practice, only the match within the dimension human orientation is present for Germany. The significant difference of the remaining dimensions indicates that the crisis-relevant elements dominate the cultural principles in Germany from the perspective of the young population. Thus, contrary to the cultural principles, a rather short-term approach to crisis management is observed, which involves a more balanced trade-off between experimental approaches and safe practices within crisis management along a more balanced enforcement of the guidelines and measures. crisis management is rather decentralized and more likely to be challenged by the population. Moreover, the well-being of the general public is given higher priority, and corona risk groups in particular are being treated in a more precautionary manner. 


\section{Outcomes and Recommendations for Crisis Management with Reference to the Culture}

The paper examined the impact of culture in crisis management by comparing the scores of the GLOBE cultural dimensions with the measurements of perceptions regarding the corona crisis management of the respective governments. By comparing the survey scores with the GLOBE cultural scores in the practices and in the values, it can be determined in which dimensions the fundamental cultural behavior could influence crisis management during a crisis and in which it deviates by being overruled through external factors as crisis relevant elements.

According to the theory of the authors Christensen et al. (2016, 887-890), a balance between the government's legitimacy and leadership capabilities in managing the containment of the crisis is essential for effective crisis management at the state level. In this context, legitimacy of the government is given if the government is valued and entrusted by the population in its crisis management. Therefore, if expectations differ from the state's implementation, society considers the government's crisis management to be deficient and on the contrary, if expectations and implementation coincide, the population is satisfied with the state's management.

Using the framework presented in the analysis part of the paper, the values of the population in the culturally defining domains can be measured and compared with the implementation in practice. According to the theory from Christensen, Lægreid and Rykkja, crisis management from the population's perspective is successful if the government's implementation of crisis management (reflected by the practice scores), match the expectations, (reflected by the desired value scores) is successful. Therefore, the framework could be used to identify and isolate barriers in crisis management that are unsuitable and thus ineffective in the event of a crisis through the deviations within the practice scores and the value scores.

The significant difference results between the survey scores and the GLOBE scores would enable to determine the type of the barrier, which allows to find and implement more efficiently targeted solutions to solve the obstacles. Thus, there could be two types of barriers: cultural barriers, in which no significant difference prevails, and external crisis barriers, in which significant difference prevails.

The outcomes show that cultural principles can shape crisis management in practice. However, values and ideals are significantly changed by the crisis. Through the developed framework, the cultural and crisis barriers could be identified and thus solutions could be found more efficiently within the specific dimension to operate a successful crisis management detached from the habitual cultural and crisis patterns.

As a recommendation to crisis management, it can be stated that cultural influence in crisis management can shape the adopted guidelines and measures, as well as the crisis behavior of the population, both subconsciously in practice. The developed framework could be used to identify and isolate crisis-driven barriers and cultural-driven barriers as cultural behaviors and cultural mindsets in crisis management requiring particular adaptation and thereby increasing efficiency in crisis management. As a result, governments or crisis management teams could take more appropriate and effective measures in crisis situations, when taking into account cultural specificities and overcoming cultural or crisis-related obstacles. 
Accordingly, the difference between the survey scores in practice and the values (see Table 7) suggests what the governments in Germany and Japan could have done better during the corona crisis from the people' s perspective, and how both governments should handle future crises by focusing on specific areas.

In both countries, the value scores are higher than the practice scores within each dimension. Therefore, crisis management in both countries should have been more centralized with longer-term oriented guidelines and measures that are enforced more strictly, and which are more restrictive in their scope. The protection of the general public should have been more prioritized. More continuous adaptation of the corona guidelines and measures depending on the situation should have taken place to achieve the best possible containment results, as well as more comprehensive information communication towards the populations.

The greatest call for action can be observed in Japan in the dimension of assertiveness (difference 2.92) and in Germany in the dimension of future orientation (difference 2.92). Accordingly, from the respondents' point of view, the governments should focus most strongly in Japan on stricter implementation of the guidelines and measures and in Germany on more long-term oriented crisis management both in the corona crisis and for future crises.

Universally, it can be seen that there is a high demand for future orientation, with the highest deviation in Germany and the second highest deviation in Japan. The overall advice for crisis management is thus that more long-term and therefore more sustainable crisis management should be pursued, rather than short-term and unprompted crisis management.

\section{Limitations, further research}

The literature on the influence of culture in crisis management, especially at the state level, is limited, making it a rather unexplored subfield of crisis management with great potential for development. In this article, the influence of culture in crisis management was investigated, represented by the central research topic of comparing the perceptions of the young population in Germany and Japan regarding the corona

Table 7 Difference between the survey values and the survey practices in Japan and Germany

\begin{tabular}{lll}
\hline GLOBE dimension & Japan & Germany \\
\hline Future orientation & 2.29 & 2.92 \\
Humane orientation & 0.07 & 1.66 \\
Assertiveness & 2.92 & 1.24 \\
Institutional collectivism & 1.82 & 1.08 \\
In-group collectivism & 1.62 & 1.19 \\
Power distance & 0.31 & 1.21 \\
Uncertainty avoidance & 0.97 & 0.99 \\
Performance orientation & 1.50 & 1.98 \\
\hline
\end{tabular}

own illustration based on the GLOBE study (House et al., 2004) 
crisis management of the respective governments with the results of the GLOBE cultural dimensions.

Given the limited survey data base, the results of the conducted survey in this article are only representative to a limited extent. A survey that could cover the different population groups and strata of a society on a nationwide basis could increase the representativeness of the results. To further increase the representativeness of the results, additional questions to each cultural dimension could be asked.

With the world growing together through globalization, there may be a potential increase in cross-border crises affecting multiple countries, like the corona crisis. In this context, it could be relevant for researchers to study the different cultural behaviors and mindsets influencing crisis management and resulting in crisis decisions by governments. This could provide insights into worst- and best-case scenarios from different countries to better prepare for and counter future crises. Accordingly, with further research, crisis management at the government level could be compared across several countries and cultural types.

\section{Declarations}

All procedures performed in studies involving human participants were in accordance with the ethical standards of the institutional and/or national research committee and with the 1964 Helsinki declaration and its later amendments or comparable ethical standards.

Informed Consent Informed consent was obtained from all individual participants included in the study.

Conflict of Interest The authors declare that they have no conflict of interest.

\section{References}

Bernhardsdóttir, Á. E. (2015). Crisis-related decision-making and the influence of culture on the behavior of decision makers: Cross-cultural behavior in crisis preparedness and Response. Springer.

Björck, A. (2016). Crisis typologies revisited: An interdisciplinary approach. Central European Business Review, 5(3), 25-37.

Boin, A., Stern, E., \& Sundelius, B. (2016). The politics of crisis management: Public leadership under pressure (Second edition) [Kindle Edition]. Cambridge University Press.

Cabinet Public Relations Office, Cabinet Secretariat, [COVID-19] Government Responses on the Coronavirus Disease 2019 (2020, July 1). https://japan.kantei.go.jp/ongoingtopics/_00013.html. Last accessed 15.02.2021.

Cabinet Public Relations Office, Cabinet Secretariat, [COVID-19] Guidelines for Lifting the State of Emergency (2020, May 25). http://japan.kantei.go.jp/ongoingtopics/_00025.html. Last Accessed 16.02.2021

Cabinet Public Relations Office, Cabinet Secretariat, [COVID-19] Guidelines for Reimposing the State of Emergency (2020, May 14). http://japan.kantei.go.jp/ongoingtopics/_00029.html. Last Accessed 16.02.2021

Christensen, T., Lægreid, P., \& Rykkja, L. H. (2016). Organizing for crisis management: Building governance capacity and legitimacy. Public Administration Review, 76(6), 887-897.

Die Bundesregierung. (2020a, May 6). Telefonschaltkonferenz der Bundeskanzlerin mit den Regierungschefinnen und Regierungschefs der Länder am 6. Mai 2020 [Press release], https://www.bundesregierung. de/resource/blob/997532/1750986/fc61b6eb1fc1d398d66cfea79b565129/2020-05-06-mpk-beschlussdata.pdf?download=1. Last Accessed 15.02.2021.

Die Bundesregierung. (2020b, October 28). Videokonferenz der Bundeskanzlerin mit den Regierungschefinnen und Regierungschefs der Länder am 28. Oktober 2020 [Press release], https://www.bundesregi erung.de/resource/blob/975226/1805024/5353edede6c0125ebe5b5166504dfd79/2020-10-28-mpkbeschluss-corona-data.pdf?download=1. Last Accessed 15.02.2021. 
Die Bundesregierung. (2020c, December 28). Telefonkonferenz der Bundeskanzlerin mit den Regierungschefinnen und Regierungschefs der Länder am 13. Dezember 2020 [Press release], https://www.bunde sregierung.de/resource/blob/975226/1827366/69441fb68435a7199b3d3a89bff2c0e6/2020-12-13-besch luss-mpk-data.pdf?download=1. Last Accessed 15.02.2021.

Die Bundesregierung, Erweiterung der beschlossenen Leitlinien zur Beschränkung sozialer Kontakte: Besprechung der Bundeskanzlerin mit den Regierungschefinnen und Regierungschefs der Länder vom 22.03.2020, https://www.bundesregierung.de/breg-de/themen/coronavirus/besprechung-der-bundeskanzlerin-mit-denregierungschefinnen-und-regierungschefs-der-laender-vom-22-03-2020-1733248. Last accessed 15.02.2021.

Hofstede, G., Hofstede, G. J., \& Minkov, M. (2010). Cultures and Organizations: Software of the Mind. Revised and expanded 3rd Edition: Intercultural Cooperation and Its Importance for Survival.

Holenweger, M., Jager, M. K., \& Kernic, F. (Eds.). (2017). Leadership in extreme situations. Springer.

House, R. J., Hanges, P. J., Javidan, M., Dorfman, P. W., \& Gupta, V. (Eds.). (2004). Culture, leadership, and organizations: The GLOBE study of 62 societies. Sage publications.

Ministry of Health, Labour and Welfare of Japan. (2020a, March 9). The Government of Japan Expert Meeting on the Novel Coronavirus Disease Control "Views on the Novel Coronavirus Disease Control", https://www.mhlw.go.jp/content/10900000/000608425.pdf. Last Accessed 16.02.2021.

Ministry of Health, Labour and Welfare of Japan. (2020b, April 1). Expert meeting on control of the novel coronavirus disease control: analysis and recommendations of the response to the novel coronavirus (COVID-19), https://www.mhlw.go.jp/content/10900000/000620826.pdf. Last Accessed 16.02.2021.

Ministry of Health, Labour and Welfare of Japan. (2020c, April 7). Basic Policies for Novel Coronavirus Disease Control: (Revised on April 7, 2020), https://www.mhlw.go.jp/content/10900000/000620733. pdf. Last Accessed 15.02.2021

Ministry of Health, Labour and Welfare of Japan. (2020d, April 16). Basic Policies for Novel Coronavirus Disease Control by the Government of Japan: (Summary),https://www.mhlw.go.jp/content/10900000/ 000624195.pdf. Last Accessed 16.02.2021.

Ministry of Health, Labour and Welfare of Japan. (2020e, May 25). Basic Policies for Novel Coronavirus Disease Control by the Government of Japan: (Summary), https://www.mhlw.go.jp/content/10900000/ 000634753.pdf. Last Accessed 16.02.2021.

National Institute of Infectious Diseases. (2021, February 1). Latest infection status, etc., https://www.niid.go. jp/niid/images/PDF/covid19/AB22thEN.pdf. Last Accessed 28.02.2021.

National Institute of Infectious Diseases, Current Situation of Infection, August 5th, 2020. https://www.niid. go.jp/niid/en/2019-ncov-e/9806-covid19-ab5th-en.html. Last Accessed 16.02.2021

National Institute of Infectious Diseases, Current Situation of Infection, January 13, 2021. https://www.niid. go.jp/niid/en/2019-ncov-e/10138-covid19-ab21th-en.html. Last Accessed 16.02.2021.

Robert Koch Institut. (2020, March 23). Täglicher Lagebericht des RKI Täglicher Lagebericht des RKI zur Coronavirus-Krankheit-2019 (COVID-19), https://www.rki.de/DE/Content/InfAZ/N/Neuartiges_Coron avirus/Situationsberichte/2020-03-23-de.pdf?_blob=publicationFile. Last Accessed 15.02.2021.

Robert Koch Institut. (2021, February 14). Täglicher Lagebericht des RKI zur Coronavirus-Krankheit-2019 (COVID-19), https://www.rki.de/DE/Content/InfAZ/N/Neuartiges_Coronavirus/Situationsberichte/Feb_ 2021/2021-02-14-de.pdf?_blob=publicationFile. Last Accessed 15.02.2021.

Robert Koch Institut, Risikobewertung zu COVID-19. https://www.rki.de/DE/Content/InfAZ/N/Neuartiges_ Coronavirus/Risikobewertung.html. Last Accessed 15.02.2021.

Robert Koch Institut, Die Pandemie in Deutschland in den nächsten Monaten - Ziele, Schwerpunktthemen und Instrumente für den Infektionsschutz (2020). https://www.rki.de/DE/Content/InfAZ/N/Neuartiges_ Coronavirus/Strategie_Ergaenzung_Covid.html. Last Accessed 15.02.2021.

Schulz, E. (2004). Bevölkerungsentwicklung in west- und ostdeutschland: Vorausschätzung bis 2050. DIW Wochenbericht, 71(33), 471-485.

Steinert, S. (2020). Corona and value change. The role of social media and emotional contagion. Ethics and Information Technology, 1-10.

Thompson, M., Ellis, R., \& Wildavsky, A. (2018). Cultural theory [Kindle Edition]. Routledge.

Publisher's Note Springer Nature remains neutral with regard to jurisdictional claims in published maps and institutional affiliations. 